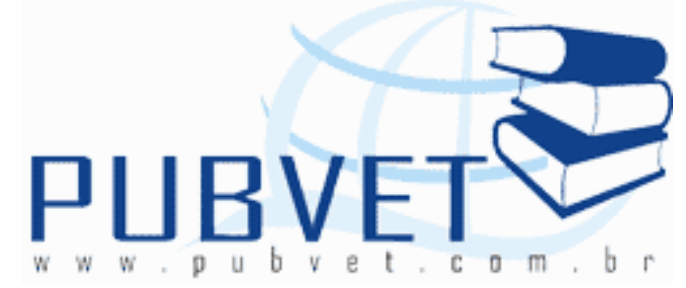

PUBVET, Publicações em Medicina Veterinária e Zootecnia.

\title{
Aspectos epidemiológicos da peritonite infecciosa felina
}

Carolina de Alvarenga $\mathrm{Cruz}^{1}$, Fernanda Cassioli de Moraes ${ }^{1}$,

Raphaella Barbosa Meirelles-Bartoli ${ }^{2}$, Daniel Bartoli de Sousa ${ }^{2}$

1Pós-graduandas do curso de Mestrado em Medicina Veterinária (Medicina Veterinária Prevetiva) - FCAV/Unesp - Câmpus de Jaboticabal - Jaboticabal/SP

${ }^{2}$ Docentes do Curso de Medicina Veterinária da Universidade Federal de Goiás (UFG), Campus Jataí, Unidade Jatobá, Laboratório de Sanidade Animal.

\section{Resumo}

A peritonite infecciosa felina (PIF) é uma doença viral sistêmica de distribuição mundial, causada por um coronavírus de RNA com fita simples que afeta tanto gatos domésticos quanto felinos selvagens. Em gatos, as coronaviroses, geralmente não causam muitos problemas, no entanto, tem-se a teoria, de que a PIF é causada pela mutação de um vírus chamado coronavírus entérico felino. O motivo dessa mutação é desconhecido, porém acredita-se que o estresse e um sistema imune deficitário possam predispor o gato a desenvolvê-la. Animais entre três meses a três anos de idade são mais afetados. Há dois tipos de PIF, a efusiva ou úmida que é considerada a forma clássica da doença, em que há formação de líquidos cavitários dando ao animal a aparência de barril, e a seca ou não efusiva que geralmente acomete grande quantidade de órgãos, além de algumas vezes o sistema nervoso central. A PIF é uma doença progressiva e fatal.

Palavras-chave: coronavírus, doença viral, gatos. 
CRUZ, C.A. et al. Aspectos epidemiológicos da peritonite infecciosa felina. PUBVET, Londrina, V. 7, N. 14, Ed. 237, Art. 1567, Julho, 2013.

\title{
Epidemiological aspects of feline infectious peritonitis
}

\begin{abstract}
The feline infectious peritonitis (FIP) is a systemic viral disease of worldwide distribution, caused by a coronavirus with single-stranded RNA that affect both domestic cats on wild cats. In cats, the coronaviroses usually do not cause many problems, however, there is the theory that IPF is caused by mutation of a virus called the feline enteric coronavirus. The reason this virus mutates in some cats and cause FIP is unknown, but it is believed that stress and a deficient immune system may predispose the cat to develop it. Animals between three months to three years of age are most affected. There are two types of FIP, the wet or effusive which is considered the classic form of the disease in which there is formation of fluid cavities giving the animal the appearance of the barrel, and the drought or not effusive that usually affects large number of bodies, and sometimes the central nervous system. The PIF is a progressive and fatal disease
\end{abstract}

Keywords: coronavirus, viral disease, cats.

\section{INTRODUÇÃO}

A Peritonite Infecciosa Felina (PIF) é sem dúvida a mais enigmática doença entre todas as coronaviroses (MURPHY, 1999). Trata-se de uma doença sistêmica e progressiva com um amplo espectro de sinais e que gera alta mortalidade (MELI et al., 2004). Nos gatos, as cepas de coronavírus têm um amplo espectro de virulência, causando desde enterites de gravidade variável até a PIF (RAPOSO et al., 1996).

A apresentação clínica da PIF é variável e por vezes complexa, refletindo as variações do vírus e a natureza da resposta imune do hospedeiro. Cerca de $50 \%$ dos gatos que são diagnosticados em todo o mundo têm menos de dois anos de idade e são gatos de raça (NORRIS, 2003).

Vários sistemas podem ser acometidos, como o respiratório, o nervoso, o oftálmico, e também a forma da PIF multissistêmica (SCOTT; BARR, 2008). 
CRUZ, C.A. et al. Aspectos epidemiológicos da peritonite infecciosa felina. PUBVET, Londrina, V. 7, N. 14, Ed. 237, Art. 1567, Julho, 2013.

Assim, o diagnóstico baseia-se no histórico, nos sinais clínicos e no grande potencial de exposição ao coronavírus, tendo como auxílio exames complementares associados ao exame histopatológico obtido pela biópsia ou eventualmente da necropsia (DAIHA, 2003).

Para minimizar o risco dos gatos desenvolverem PIF, podem-se alterar as práticas de criação, particularmente em colônia, mas isso é, em grande parte, destinado a evitar ou reduzir a prevalência da infecção subjacente com cepas produtoras de enterite do FCoV (SPARKES, 2006).

\section{DEFINIÇÃO}

A Peritonite Infecciosa Felina (PIF) é uma doença infecto-contagiosa, sistêmica imunomediada e progressivamente fatal que acomete não somente os gatos domésticos (Felis catis) como também outros felinos (DAIHA, 2003). É caracterizada por um início insidioso, febre persistente que não melhora, reação tecidual piogranulomatosa, acúmulo de efusões exudativas nas cavidades corporais e alta mortalidade (SCOTT; BARR, 2008).

\section{HISTÓRICO}

A PIF foi reconhecida pela primeira vez em 1950 e é uma importante causa de mortalidade de gatos jovens por doença infecciosa em gatis e abrigos com pedigree. A etiologia da infecção por coronavírus foi primeiramente relatada por Ward em 1970. Estudos soroepidemiológicos foram conduzidos primeiramente usando-se tecidos infectados pelo vírus da peritonite infecciosa felina (VPIF) como substrato para imunofluorescência indireta (VENNEMA et al, 1998). Praticamente todos os gatos normais de famílias que tinham animais que morriam em decorrência da PIF, eram soropositivos sugerindo que a doença é a manifestação infrequente de uma infecção comum. No entanto, quando VPIF foi isolado de animais infectados naturalmente e transmitida experimentalmente para gatos de laboratório causou PIF fatal ao invés da doença inaparente (VENNEMA et al., 1998 ). 
CRUZ, C.A. et al. Aspectos epidemiológicos da peritonite infecciosa felina. PUBVET, Londrina, V. 7, N. 14, Ed. 237, Art. 1567, Julho, 2013.

\section{IMPORTÂNCIA DA DOENÇA}

Os vírus das coronaviroses felinas estão intimamente relacionados ao vírus da gastroenterite transmissível dos suínos, e ao coronavírus canino, além de outras coronaviroses de importância econômica (RAPOSO et al., 1996).

A doença não é uma zoonose, no entanto é de extrema importância para criadores de gatos, uma vez que animais que convivem com muitos outros, como ocorre em gatis, apresentam a doença com maior frequência (SPARKES, 2006).

\section{ETIOLOGIA}

Os coronavírus pertencem a um grupo de coronavírus muito proximamente aparentados, que inclui o vírus da gastroenterite transmissível (TGEV, transmissible gastroenteritis vírus) dos suínos, o recém-surgido coronavírus respiratório suíno, o coronavírus canino ( $\mathrm{CCV}$, canine coronavirus) e um coronavírus humano (SPARKES, 2006).

Para LAI; HOLMES, 2001 as coronaviroses podem ser divididas em 3 grupos sorológicos distintos. Em cada sorogrupo as viroses são classificadas de acordo com seu hospedeiro natural, sequência de nucleotídeo, e relações sorológicas. A maioria das coronaviroses naturalmente infecta uma espécie animal ou, na maioria das vezes, um número limitado de espécies próximas. 0 Grupo I inclui o vírus da gastroenterite transmissível dos suínos, o coronavírus respiratório suíno, o coronavírus canino, o vírus da peritonite infecciosa felina, o coronavírus entérico felino, e o coronavírus humano 229E. Já o grupo II inclui o vírus da hepatite do rato, o coronavírus bovino, o vírus da sialodacriadenite de ratos, o coronavírus dos coelhos, o coronavírus do peru e o coronavírus humano OC43. Finalmente o grupo III, inclui o vírus da bronquite infecciosa das aves (MURPHY et al., 1999).

Segundo SPARKES, 2006 existem apenas dois sorotipos de FCoV, referidos como tipos I e II, que são definidos por ensaios de neutralização. Acredita-se que os FCoV do tipo II surgiram por recombinação com o CCV, 
CRUZ, C.A. et al. Aspectos epidemiológicos da peritonite infecciosa felina. PUBVET, Londrina, V. 7, N. 14, Ed. 237, Art. 1567, Julho, 2013.

resultando na incorporação do gene da espícula do CCV (o gene que codifica a proteína da espícula da membrana) no genoma do FCoV.

A replicação do vírus in vivo tanto pode ser disseminada causando infecções sistêmicas, quanto restritas a um pequeno número de tipo de células, como células epiteliais do sistema respiratório ou trato entérico e macrófagos causando infecções localizadas (LAI; HOLMES, 2001).

\subsection{CARACTERÍSTICAS MORFOLÓGICAS}

Os coronavírus são vírus RNA de fita simples, medindo de 80 a $220 \mathrm{~nm}$ e têm formato esférico (no caso das coronaviroses) ou 120 a 140 nm em formato de disco, rim, ou bastonete (no caso das toroviroses) (MURPHY et al, 1999). Por conterem o maior genoma de RNA conhecido, são altamente suscetíveis à mutação espontânea durante a replicação (SPARKES, 2006). O envelope possui externamente, proteínas na forma de espículas, que conferem ao vírus um aspecto de coroa, daí o nome de Coronavírus. Estruturalmente é constituído por três proteínas: nucleocapsídeo, glicoproteína de membrana e o peplômero (projeções superficiais). Embora os coronavírus sejam relativamente instáveis e suscetíveis aos desinfetantes usados com mais frequência, estudos comprovam que o FCoV pode permanecer viável no ambiente entre 2 e 7 semanas, sugerindo que a não adoção de uma adequada prática de higiene pode contribuir para a ocorrência da infecção (SPARKES, 2006).

\subsection{ASPECTOS PATOGÊNICOS}

Há evidências consideráveis, mas não provas absolutas de que a mutação do coronavírus entérico desenvolve as características patológicas e invasivas que estão associadas com o vírus da PIF. A partir de estudos em gatos infectados experimentalmente, foi demonstrado que o resultado da infecção não depende somente da estirpe do vírus, mas também da dose infectante e da via de entrada, a idade do gato, e das condições de habitação e criação (MURPHY et al 1999). 
CRUZ, C.A. et al. Aspectos epidemiológicos da peritonite infecciosa felina. PUBVET, Londrina, V. 7, N. 14, Ed. 237, Art. 1567, Julho, 2013.

A variação na virulência entre as cepas do vírus está relacionada com a sua capacidade de infectar e se replicar em macrófagos. Este tropismo parece resultar de mutações em genes que codificam a glicoproteína $S$, o peplômero, proteína responsável pela fixação viral e a membrana de fusão, e o alvo habitual de vírus anticorpos neutralizante. Mutações endógenas são as prováveis causa da doença em gatos que vivem em ambientes isolados e que desenvolvem a doença tardiamente na vida (MURPHY et al, 1999).

\section{EPIDEMIOLOGIA}

\subsubsection{DISTRIBUIÇÃO}

A infecção por FCoV é onipresente nas populações domésticas felinas por todo o mundo. Pesquisas sorológicas demonstram que tipicamente 25 a $40 \%$ dos gatos de estimação de ambiente doméstico são FCoV soropositivos, enquanto essa porcentagem sobe para 80 a $100 \%$ no caso de gatos provenientes de gatis de reprodução e outros grandes gatis. Apesar desse alto nível de exposição por FCoV em populações felinas, a PIF permanece uma doença relativamente rara. Esse fato, junto com outras observações, sugere ser provável que a maioria das infecções por FCoV naturais seja por biótipos do FECoV e que as variantes do vírus da PIF são relativamente incomuns (SPARKES, 2006).

Diferentes fatores de interação entre hospedeiro e agente etiológico podem também influenciar na prevalência da doença e sua expressão clínica, como tempo de exposição ao vírus, suscetibilidade genética, capacidade imune, estresse e as infecções intercorrentes com os vírus da leucemia felina (FeLV) e da imunodeficiência felina (FIV) (DAIHA, 2003).

\subsubsection{CADEIA EPIDEMIOLÓGICA}

\subsubsection{FONTE DE INFECÇÃO (FI)}

Felinos domésticos e selvagens infectados. Os portadores do coronavírus são um dos maiores responsáveis pela disseminação do VPIF. Estudos têm demonstrado que $42 \%$ a $75 \%$ desses animais eliminam constantemente as 
CRUZ, C.A. et al. Aspectos epidemiológicos da peritonite infecciosa felina. PUBVET, Londrina, V. 7, N. 14, Ed. 237, Art. 1567, Julho, 2013.

partículas virais nas fezes, infectando vários animais em gatis ou em locais com uma alta densidade de felinos (DAIHA, 2003).

\subsubsection{VIA DE ELIMINAÇÃO (VE)}

O vírus é encontrado nas secreções e excreções de gatos infectados, que, durante a fase aguda da doença, o transmitem, via fecal-oral, oral-oral, oralnasal (RAPOSO, 1996).

\subsubsection{MODO DE TRANSMISSÃO (MT)}

O modo de transmissão ainda não está totalmente esclarecido. Supõe-se que a infecção inicial resulte da ingestão ou inalação do coronavírus presente na saliva, secreções respiratórias, urina e fezes dos gatos infectados, assim como o uso coletivo de fômites e de vasilhas sanitárias e o hábito de lambeduras mútuas, que também constituem importantes meios de transmissão (DAIHA, 2003). Comumente, os filhotes serão infectados de gatos adultos assintomáticos que disseminam o vírus em suas fezes (SPARKES, 2006), no entanto as gatas portadoras do FIPV podem também infectar seus filhotes via placentária ou no período neonatal (DAIHA, 2003).

\subsubsection{PORTA DE ENTRADA (PE)}

A porta de entrada é a cavidade oral e nasal (SPARKES, 2006).

\subsubsection{HOSPEDEIROS SUSCEPTÍVEIS (HS)}

Os felídeos são os hospedeiros susceptíveis (DAIHA, 2003).

\section{PATOGENIA}

A patologia da PIF é tipicamente caracterizada por graves danos inflamatórios e sistêmicos das membranas serosas e lesões piogranulomatosas generalizadas que ocorrem nos pulmões, fígado, tecido linfático e cérebro. Evidências sugerem que o sistema imune do hospedeiro é crucial nesta patogênese. A depleção de células T-profundas e de tecidos linfáticos, e 
CRUZ, C.A. et al. Aspectos epidemiológicos da peritonite infecciosa felina. PUBVET, Londrina, V. 7, N. 14, Ed. 237, Art. 1567, Julho, 2013.

alterações na expressão de citocinas são observadas em fase final da PIF (BROWN et al., 2009).

Gatos que produzem anticorpos, mas não conseguem gerar uma resposta imune celular adequada, desenvolvem a doença efusiva, que na verdade é um complexo de hipersensibilidade imediata por uma reação imunomediada. Já quando o anticorpo está presente, a absorção de complexos virais de anticorpos infecciosos pelos monócitos e macrófagos é facilitada, com intensificação de anticorpos, pois a presença de imunoglobulinas contra o FECV aumenta a entrada do vírus em macrófagos (ligação do complexo antígenoanticorpo) ao receptor do coronavírus felino (OLIVEIRA, 2003). Então, o vírus replica-se nessas células e o progresso da doença é acelerado, causando a doença não efusiva (MURPHY et al., 1999).

Os felinos que desenvolvem uma rápida reposta imunomediada por células, aparentemente não desenvolvem a doença embora abriguem o vírus em estado latente e persistente, podendo fornecer o estímulo antigênico para manter o seu estado imunológico. Nestes gatos a infecção pode ser reativada por infecções intercorrentes que são imunossupressoras, como a leucemia felina ou a doença pelo vírus da imunodeficiência felina (MURPHY et al., 1999).

O vírus replica-se em células epiteliais do trato respiratório superior da orofaringe onde anticorpos antivirais são produzidos, e é capturado pelos macrófagos. Dentro de monócitos/macrófagos, o vírus é transportado por todo o corpo, se localizando em várias paredes venosas e locais perivasculares. A replicação perivascular local e a subsequente reação tecidual piogranulomatosa produzem a lesão clássica da PIF (SCOTT; BARR; 2008).

\section{SINAIS CLÍNICOS}

O curso da doença é estabelecido rapidamente após a infecção (MURPHY et al., 1999). Este varia de alguns dias a alguns anos. A doença efusiva tende a ter duração um pouco mais curta que a não efusiva e a maioria dos casos possui curso de poucas semanas (SPARKES, 2006) 
CRUZ, C.A. et al. Aspectos epidemiológicos da peritonite infecciosa felina. PUBVET, Londrina, V. 7, N. 14, Ed. 237, Art. 1567, Julho, 2013.

A PIF possui uma grande variedade de sinais clínicos, dependendo da virulência da cepa, da resposta imune do hospedeiro e do sistema orgânico acometido (SCOTT; BARR, 2008). Os sinais variam com a distribuição das lesões e extensão da efusão peritonial e/ou pleural (JONES; HUNT; KING, 2000). Esta doença apresenta duas formas, úmida ou efusiva que tem como alvo as cavidades corporais, e a seca ou não efusiva que acomete uma variedade de órgãos (SCOTT; BARR; 2008).

Têm-se como achados anamnésicos o início insidioso, a perda de peso gradual e diminuição de apetite, parada de desenvolvimento em filhotes, febre persistente (flutuante) e a não melhora do quadro com antibióticos. Durante o exame físico percebe-se depressão; condição deficiente; parada do crescimento; perda de peso; pelagem sem brilho, áspera; icterícia; à palpação o abdome apresentará massas (granulomas ou piogranulomas) dentro do omento, na superfície de vísceras (especialmente os rins) e dentro da parede intestinal (os linfonodos mesentéricos podem estar aumentados). Pode-se também encontrar lesões oculares como uveíte anterior, precipitados ceráticos, alteração da cor da íris, pupilas de formato irregular e lesões neurológicas do tronco cerebral, cerebrocortical ou da medula espinhal (SCOTT; BARR; 2008). $\mathrm{Na}$ clássica PIF efusiva, esses sinais são acompanhados por uma distensão abdominal progressiva, devido ao acúmulo de um líquido viscoso amarelo ascético, cuja quantidade pode variar de alguns mililitros a mais de um litro, conferindo ao abdome um aspecto de barril (SCOTT; BARR; 2008).

\section{DIAGNÓSTICO}

\subsection{LABORATORIAL}

A sorologia baseia-se geralmente em testes de imunofluorescência (RIF) ou ensaios imunoabsorventes ligados à enzima (ELISA). Porém, o teste não consegue distinguir o tipo de cepa do FCoV, se a infecção é atual ou anterior, ou se o gato é suscetível ao desenvolvimento de PIF. Logo, a interpretação dos títulos de coronavírus exige grande cuidado, já que a presença de um título positivo pode representar a alta prevalência de soropositividade na população 
CRUZ, C.A. et al. Aspectos epidemiológicos da peritonite infecciosa felina. PUBVET, Londrina, V. 7, N. 14, Ed. 237, Art. 1567, Julho, 2013.

felina de estimação geral e prevalência bastante alta de soropositividade em ambientes domésticos com muitos gatos, onde 80 a 100\% são soropositivos (SPARKES 2006).

Tanto o RIF quanto o ELISA fornecerão os títulos de anticorpos contra o coronavírus e medem os anticorpos predominantemente dirigidos contra as proteínas internas do vírus. Um título coronaviral acima de 1:3200 está associado à forma não efusiva da PIF, ao passo que um título entre 1:25 e 1:3200 está associado com a forma efusiva da doença (DAIHA, 2003).

Importante comentar que, um título de anticorpos positivo para coronavírus num gato sadio não garante proteção para PIF, não indica se o gato apresentará PIF mais tarde ou se o felino é um risco comprovado para outros gatos (DAIHA, 2003).

Um diagnostico presuntivo ante mortem de gatos com sinais clínicos de PIF mais sugestivo pode ser realizado por da combinação de uma tríade de indicadores como linfopenia, um título de anticorpo para coronavírus acima de 1:160 e hiperglobulinemia, havendo uma probabilidade de $88,9 \%$ de apresentar PIF confirmada na necropsia (DAIHA, 2003).

A análise de derrames (líquido abdominal) permanece um dos testes rotineiros mais valiosos para o diagnóstico de PIF. Esta é a razão porque, mesmo em casos suspeitos de doença não efusiva, é válido empreender investigação para avaliar se há pequena quantidade de derrame e se pode ser aspirada. Em casos de PIF, o fluido é tipicamente cor de palha e viscoso, em razão de seu teor protéico, e pode formar um coágulo de fibrina se for deixado em repouso (SPARKES, 2006).

Estudos demonstram que em casos de derrame de PIF, o teor protéico total do fluido é acima de $35 \mathrm{~g} / \mathrm{L}$, sendo típicos níveis ao redor de $60 \mathrm{~g} / \mathrm{L}$. Além da proteína total, deve-se determinar sempre a proporção de albumina: globulina, pois os casos de PIF apresentam invariavelmente concentração de globulina maior ou igual a $50 \%$ do teor protéico total. A contagem celular total dos derrames de PIF é geralmente inferior a $20 \times 10^{6} / \mathrm{mL}$ com predominância de macrófagos e neutrófilos não degenerados (SPARKES, 2006). . 
CRUZ, C.A. et al. Aspectos epidemiológicos da peritonite infecciosa felina. PUBVET, Londrina, V. 7, N. 14, Ed. 237, Art. 1567, Julho, 2013.

Os ensaios de Reação em Cadeia Polimerase (PCR) são aplicados para detecção de sequelas do FCoV em gatos infectados. Estudos demonstraram que, em casos confirmados de PIF, o teste RT-PCR, para detectar material genômico do FCoV de amostras sanguíneas, é normalmente positivo em 80 a $90 \%$ dos casos. Contudo, quando se aplica o mesmo teste em gatos saudáveis provenientes de gatis endêmicos para FCoV, estudos mostram que muitos destes também são RT-PCR positivos (SPARKES, 2006).

Dessa forma, os ensaios de RT-PCR atualmente disponíveis não conseguem distinguir entre cepas produtoras de PIF virulentas do FCoV e as cepas produtoras de enterite menos virulentas. Sugerindo, assim que este teste possui pouco valor no diagnóstico rotineiro de PIF (SPARKES, 2006).

Em gatos com manifestações no SNC relacionadas à PIF, a análise do fluido cerebroespinhal (CSF) pode fornecer informações adicionais valiosas (SPARKES, 2006).

\subsection{LESÕES ANATOMOPATOLÓGICAS}

Pode ocorrer uma ampla variedade de lesões. No caso de doença efusiva, estas consistem normalmente em depósitos fibrinosos e pequenos piogranulomas no omento e nas superfícies serosas da maioria dos órgãos abdominais e também das superfícies pleurais (SPARKES, 2006). Está presente um exsudato granular branco-acinzentado sobre todas as superfícies serosas, e é especialmente espesso sobre o fígado e baço. Macroscopicamente a cavidade abdominal contém líquido excessivo, frequentemente até 1 litro. 0 líquido é amarelo, viscoso, e transparente, embora possa conter flocos de fibrina. Um exsudato e uma lesão inflamatória semelhante podem afetar a cavidade pleural e o pericárdio (JONES; HUNT; KING, 2000).

Em casos de doença não-efusiva, as lesões granulomatosas são geralmente muito maiores e circundadas por mais fibrose, há também necrose em órgãos abdominais, olhos e SNC (SPARKES, 2006). Com frequência estão presentes muitos nódulos granulomatosos na superfície do pâncreas, rim, pulmão, e outros órgãos, as meninges podem ser opacas, e podemos observar 
CRUZ, C.A. et al. Aspectos epidemiológicos da peritonite infecciosa felina. PUBVET, Londrina, V. 7, N. 14, Ed. 237, Art. 1567, Julho, 2013.

sinais macroscópicos de panoftalmite (JONES; HUNT; KING, 2000). Nos casos prolongados a organização do exsudato fibroso pode resultar numa grave distorção das vísceras abdominais (JONES; HUNT; KING, 2000). Pode-se observar também meningite e meningoencefalite piogranulomatosas em animais que desenvolvem a forma não efusiva. (OLIVEIRA et al., 2003)

Microscopicamente, a peritonite é uma inflamação fibrinosa clássica, consistindo de uma camada de fibrina de espessura variável, que contém restos celulares sobre uma camada de neutrófilos, linfócitos e macrófagos. Fibroplastia e proliferação dos capilares podem acompanhar o exsudato em casos muito prolongados. O processo inflamatório pode estender-se por baixo da serosa, até qualquer tecido afetado (JONES;HUNT; KING, 2000).

Abrangendo outros órgãos, como o fígado, pâncreas, rim, linfonodos, camadas musculares do trato gastrintestinal, meninges, e olho, as lesões microscópicas consistem de muitos focos de necrose ou inflamação granulomatosa, que são habitualmente observados estendendo-se a partir da parede de um vaso sanguíneo, e incorporando essa estrutura (JONES; HUNT; KING, 2000). Uma característica típica da PIF é o embainhamento perivascular, em que macrófagos e outras células inflamatórias infectadas tendem a se agregar ao redor de pequenas vênulas nos tecidos-alvo $O$ infiltrado celular se compõe de macrófagos, linfócitos, plasmócitos e neutrófilos. Aparentemente a lesão tem o aspecto de uma vasculite primária, e evidências sugerem que essa lesão é mediada por mecanismos imunes. Foram demonstrados complexos imunes circulantes nos gatos afetados, e também a presença desses complexos em glomérulos renais e nas lesões granulomatosas. Também foi demonstrada coagulação intravascular disseminada em gatos afetados, um achado observado em outras moléstias virais de complexo imune (SPARKES, 2006).

Histologicamente, as principais alterações consistem de graus variáveis de perivasculite e vasculite piogranulomatosas, principalmente em arteríolas e veias de pequeno calibre em diversos órgãos (OLIVEIRA et al., 2003). 
CRUZ, C.A. et al. Aspectos epidemiológicos da peritonite infecciosa felina. PUBVET, Londrina, V. 7, N. 14, Ed. 237, Art. 1567, Julho, 2013.

\subsection{DIFERENCIAL}

Infecção com as cepas produtoras de enterite do FCoV raramente é grave o bastante para exigir diagnóstico específico do agente etiológico subjacente. Enterite leve e transitória em filhotes pode decorrer de muitos agentes diferentes, e a investigação é geralmente empreendida apenas quando os sinais são mais persistentes e particularmente graves (SPARKES, 2006).

A PIF permanece uma doença de difícil diagnóstico antemortem. No entanto, é relativamente fácil diagnosticar a forma úmida ao exame clínico (SCOTT; BARR, 2008). Uma das dificuldades para identificar a forma seca, é a ampla diversidade de apresentações clínicas com essa doença, tornando-a consideração no diagnóstico diferencial de uma variedade bastante ampla de sinais (SPARKES, 2006). Como diagnóstico diferencial pode-se citar febre de origem indeterminada, doença cardíaca que causa efusão pleural, lesões de linfoma, especialmente nos rins (à palpação), tumores do SNC, doença respiratória, pan-esteatite (doença da gordura amarela, enterite causada por panleucopenia) (SCOTT; BARR, 2008).

Para a PIF efusiva, ainda como diagnóstico diferencial, podem ser citados glomerulonefrite, enteropatias, peritonite bacteriana, toxoplasmose, tuberculose, gestação, traumatismo e hérnia diafragmática. Na não efusiva deve-se descartar também infecções fúngicas (criptococose e histoplasmose). Entretanto, essa dificuldade é aumentada pela falta de testes laboratoriais rotineiros específicos para confirmar as suspeitas clínicas de um diagnóstico (SPARKES, 2006)

\section{TRATAMENTO}

Quando se desenvolvem sinais de PIF, esta se torna quase sempre doença incurável e fatal (SPARKES, 2006). Dentre os cuidados de saúde apropriados estão tratamento hospitalar ou ambulatorial, dependendo do estágio e da gravidade da doença e proporcionar ao animal bons cuidados de enfermagem (SCOTT; BARR, 2008). 
CRUZ, C.A. et al. Aspectos epidemiológicos da peritonite infecciosa felina. PUBVET, Londrina, V. 7, N. 14, Ed. 237, Art. 1567, Julho, 2013.

Deve-se realizar a paracentese terapêutica para aliviar a pressão decorrente da ascite excessiva ou de efusões pleurais e é extremamente importante incentivar o gato acometido a se alimentar (SCOTT; BARR, 2008). Apesar do tratamento da PIF ser de suporte e sintomático, (SPARKES, 2006), baseia-se no uso de antiinflamatórios e imunossupressores, a fim de evitar a formação de anticorpos, imunocomplexos e inflamação imunomediada (DAIHA, 2003).

\section{PROgnóstico}

O prognóstico é grave assim que surgem os sinais típicos; mortalidade próxima de 100\% (SCOTT; BARR, 2008).

\section{CONTROLE E PREVENÇÃo}

A conduta profilática frente à PIF, como um problema de doença infecciosa, requer uma atenção especial quanto ao perfil sorológico dos gatos para coronavírus e o manejo destes animais, principalmente em locais que agregam um grande número de felinos como gatis criatórios, abrigos, clínicas e hospitais veterinários (DAIHA, 2003).

A presença de coronavírus no gatil criatório deve ser averiguada com realização de testes sorológicos periodicamente. Nos gatis de gatos soronegativos para o coronavírus, recomenda-se introduzir somente gatos testados. Nos gatis de animais soropositivos para coronavírus deve-se isolar os felinos com sintomatologia clínica de PIF (DAIHA, 2003).

Medidas básicas de controle da PIF incluem: desinfecção das gaiolas, pisos vasilhas sanitárias e fômites com hipoclorito de sódio diluído em água, chegando a uma concentração final de $0,175 \%$ de hipoclorito de sódio; a higiene pessoal das pessoas que manejam os gatos; a não aglomeração de animais e o não acasalamento com parentesco próximo. (DAIHA, 2003).

Desenvolveu-se vacina contra PIF comercial com base na administração intranasal de um isolado mutante do vírus da PIF. Relata-se que o vírus da PIF 
CRUZ, C.A. et al. Aspectos epidemiológicos da peritonite infecciosa felina. PUBVET, Londrina, V. 7, N. 14, Ed. 237, Art. 1567, Julho, 2013.

produz resposta de IgA na mucosa local e resposta imunológica mediada por células sistêmica ( SPARKER, 2006).

Apesar de alguns estudos experimentais terem falhado em demonstrar eficácia vacinal, vários apresentaram grau razoável de proteção induzido pela vacinação. Sob condições de campo, há evidências de eficácia quando administrada em gatos soronegativos ou gatos com baixos títulos de anticorpos contra o FCoV (SPAKER, 2006).

\section{CONCLUSÃO}

Assim, conclui-se que, apesar da PIF não ser uma doença tão comum em gatos ela é de grande importância, uma vez que tem geralmente um curso fatal, acarretando prejuízo aos criadores de felinos e perda emocional para os proprietários de gatos. Portanto, é necessário realizar uma adequada prevenção e controle da doença, evitando aglomeração de animais e doenças que possam acarretar em déficit do sistema imune, além de se fazer higienização ambiental e de possíveis fômites de forma correta e eficaz, para minimizar os riscos do gato se infectar pelo coronavírus e vir a desenvolver a PIF.

\section{REFERÊNCIAS BIBLIOGRÁFICAS}

BROWN, M. A. et al. Genetics and Pathogenesis of Feline. Emerging Infectious Diseases, Maryland, v. 15, n. 9, p.1445-1452, set. 2009. Disponível em: <http://www.cdc.gov/eid/content/15/9/pdfs/1445.pdf>. Acesso em: 08 de dezembro de 2012.

DAIHA, M. C. Peritonite Infecciosa Felina. In: SOUZA, Heloísa Justen M. de. Coletâneas em medicina e cirurgia Felina. Rio de Janeiro: L. F. Livros de Veterinária, 2003. Cap. 29, p. 363-373.

JONES, T. C.; HUNT, R. D.; KING, N. W. Moléstias causadas por agentes virais: peritonite infecciosa felina. In: JONES, Thomas Carlyle; HUNT, Ronald Duncan; KING, Norval W. Patologia Veterinária. 6. ed. Barueri: Manole, 2000. Cap. 8, p. 361-362.

LAI, M. M. C.; HOLMES, K. V. Coronaviridae: The Viruses and Their Replication. In: FIELDS, Bernard N. et al. Fields- Virology. 4. ed. New York: Lippincott Williams \& Wilkins, 2001. Cap. 35, p. 951-969. 
MELI, M. et al. High viral loads despite absence of clinical and pathological findings in cats experimentally infected with feline coronavirus (FCoV) type I and in naturally FCoV-infected cats. Journal Of Feline Medicine And Surgery, Zürich, n. , p.69-81, 2004. Disponível em: <http://www.sciencedirect.com/science?_ob=ArticleURL\&_udi=B6WJC-4BRTD 9P-7\&_user $=972052 \& \_c o v e r D a t e=04 \% 2 F 30 \% 2 F 2004 \& \_r d o c=1 \&$ fmt $=$ high \&_ orig=search\&_sort $=d \&$ _docanchor $=\&$ view $=c \&$ _searchStrId $=1198619070 \&$ rerunOrigin =schola r.google\&_acct $=$ C000049647\&_version $=1 \&$ _urlVersion $=0 \&$ userid $=972052 \& \mathrm{md} 5=\mathrm{b} 4 \mathrm{f} 6 \mathrm{bbe} 379$ 7966ffa278daba2b69ec67>. Acesso em: 08 de dezembro de 2012.

MURPHY, F. A. et al. Veterinary Virology. 3. ed. California: An Imprint Of Elsevier, 1999.

NORRIS, J. Feline Infectious Peritonitis. Australian College Of Veterinary Scientists Science Week 2003 - Small Animal Medicine Chapter Meeting, Sydney, p.60-61, 2003. Disponível em: <http://samedicine.acvsc.org.au/samedicine_assets/documents/2003\%20sam\%20proceeding s/norris.pdf>. Acesso em: 08 de dezembro de 2012.

OLIVEIRA, F. N. et al. Peritonite infecciosa felina: 13 casos. Ciência Rural, Santa Maria, v. 33, n. 5, p.905-911, set/out. 2003. Disponível em: <http://www.scielo.br/pdf/cr7138.pdf>. Acesso em: 08 de dezembro de 2012.

RAPOSO, J. B. et al. Persistence and Evolution of Feline Coronavirus in a Closed Cat-Breeding Colony. Revista da Fzva, Uruguaiana, v. 2/3, n. 1, p.62-70, 1995/1996. Disponível em: $<$ http://revistaseletronicas.pucrs.br/ojs/index.

php/fzva/article/viewFile/1952/1456>. Acesso em: 08 de dezembro de 2012.

SCOTT, F. W; BARR, S. C. Peritonite Infecciosa Felina (PIF). In: TILLEY, Larry P.; SMITH JUNIOR, Francis W. K. Consulta Veterinária em 5 minutos. Barueri: Manole, 2008. p. 11301131.

SPARKES, A. H.. Infecção por coronavírus felino. In: CHANDLER, E. A.; GASKELL, C. J.; GASKELL, R. M. (Comp.). Clínica e terapêutica em felinos. 3. ed. São Paulo: Roca, 2006. Cap. 25, p. 508-518.

VENNEMA, $\mathrm{H}$. et al. Feline Infectious Peritonitis Viruses Arise by Mutation. California, p.150157, 1998. Disponível em: <http://www.sciencedirect.com/ science?_ob=MiamiImageURL\&_imagekey=B6WXR-45J58YK-H-1\&_cdi $=7165 \&$

_user $=972052 \& \_$pii $=$S0042682298990456\&_check $=y \&$ \& orig $=$ search\&_coverDate $=03 \% 2 \mathrm{~F} 30 \%$ 2F1998\&view $=c \& w c h p=d G L b V t z-z S k z S \& m d 5=d 2 a 4 c 1 a 9 c 3 b e 3$

7c84887be3d851ed430\&ie=/sdarticle.pdf>. Acesso em: 08 de dezembro de 2012. 